\title{
Ele e Ela
}

\section{He and She}

Autor: Anton Pávlovitch Tchékhov

Tradutor: Melissa Teixeira Siqueira Barbosa

Edição: RUS Vol. 11. Nº 15

Data: Junho 2020

https://doi.org/10.11606/issn.2317-4765. 


\section{Ele e Ela ${ }^{1}$ \\ Anton Pávlovitch Tchékhov \\ Tradução de Melissa Teixeira Siqueira Barbosa*}

Resumo:"Ele e Ela" (Он и Она) foi publicado pela primeira vez pela revista "Mirskói Tólk" (Мирской толк), em 23 de Julho de 1882. Dois anos mais tarde, em 1884, foi publicado na coletânea "Contos de Melpômene" (Сказки Мельпомены), após sofrer algumas alterações. 0 escritor e dramaturgo Anton Tchékhov (1860-1904) assinou esta obra utilizando um de seus pseudônimos, A. Tchekhonté, derivado de seu sobrenome. No presente conto acompanhamos o relacionamento conflituoso entre uma cantora famosa e seu marido em meio ao ritmo agitado de banquetes e de personagens do meio teatral.
Abstract: "He and She" (Он и Она) was published for the first time on 23 July 1882 by the magazine "Mirskoi Tolk"(Мирской толк). Two years later, in 1884, after undergoing some changes, it was published in the anthology "The Tales of Melpomene" (Сказки Мельпомены). Chekhov signed this work under the alias A. Chekhonte, which was derived from his surname. In the present short story we follow the conflictual relationship between a famous singer and her husband amidst the frantic pace of the the feasts and characters of the theatrical sphere.

Palavras-chave: Literatura Russa; Tradução; Conto; Tchékhov Keywords: Russian Literature; Translation; Short Story; Chekhov 


\section{Introdução}

*Graduanda em Letras Português/ Italiano pela Universidade Federal Fluminense.

E-mail: melissa.t.siqueira@gmail. com https://orcid.org/00000001-6288-783X
"Ele e Ela" é uma obra solidamente construída sobre os pilares da ironia, conhecidamente um dos traços tchekhovianos mais marcantes. Além disso, o conto também é rico em temas que muitas vezes são apresentados de forma polarizada, como: o feminino e o masculino, o amor e o ódio, a fama e o anonimato, o afeto e o desprezo, etc.

Além do cuidado em manter viva essa dualidade da obra, ao iniciar a tradução deste conto, uma das preocupações foi em procurar transmitir com fidelidade o tom e o estilo do autor para o português e, ao mesmo tempo, preservar, na medida do possível, o ritmo do texto original, mas sem comprometer a fluidez do texto de chegada. ${ }^{2}$

Ao analisar o original, as repetições foram um dos principais pontos problemáticos que surgiram, um plausível exemplo disso é a recorrência constante dos pronomes pessoais. $O$ pronome "On" (Ele) desde o título até a última frase é repetido quarenta vezes, enquanto "Ona" (Ela) é repetido sessenta e três vezes, atentando para o fato de que essa contagem abarca apenas a recorrência desses pronomes no caso nominativo.

É possível observar que o emprego dos pronomes na língua russa é muito comum, enquanto em português a tendência em geral é suprimir o pronome pessoal quando acompanhado de verbo. Durante o processo de tradução algumas, dessas repetições foram mantidas sempre que possível, enquanto em outras foram estrategicamente suprimidas, visando evitar que 0 texto traduzido perdesse a sua vivacidade e desenvoltura.

A opção por suprimir as repetições, por mais simples que possa parecer à primeira vista, carrega em si um certo nível de complexidade, porque o tradutor precisa ter um olhar sensível para tentar interpretar a intenção do autor ao empregar cada elemento que compõe a sua obra. Ademais, muitas vezes

1Texto original em russo disponível em: <http://chehov-lit.ru/chehov/text/on-i-ona.htm>. Acesso em: Setembro de 2018.

2 QUEIROZ, 2008, p.48. 
o tradutor também precisa se colocar no lugar do leitor, na tentativa de prever como será a recepção do trabalho.

Embora a supressão de alguns elementos tenha sido um passo necessário para a construção do texto alvo, não se podes deixar de observar a riqueza que esses detalhes trazem ao texto original. A repetição dos pronomes pessoais "ele" e "ela" está diretamente ligada ao cerne da obra e salienta ainda mais a oposição entre a duas personagens principais, que também executam o trabalho de narradores.

\section{Ele e Ela}

Eles estão em peregrinação. Paris é a única cidade na qual eles passam meses, já em relação à Berlim, Viena, Nápoles, Madrid, São Petersburgo e outras capitais, eles são sovinas. Em Paris eles se sentem quasi ${ }^{3}$ em casa; para eles Paris é a capital, a residência, o resto da Europa é uma província estúpida e entediante que apenas pode ser observada através das cortinas abaixadas do grand-hôtel ou do proscênio. Eles não são velhos, mas já passaram duas ou três vezes por todas as capitais européias. Já estão cansados da Europa e começam a conversar sobre uma viagem para a América, e vão conversar até o momento em que eles estejam convencidos de que a voz dela não é tão maravilhosa assim para ser apresentada em ambos os hemisférios.

Avistá-los é difícil. Não se pode vê-los nas ruas, porque andam de carruagem quando está escuro, à noite e de madrugada. Dormem até a hora do almoço. Costumam acordar de mau-humor e não recebem ninguém. Recebem apenas em horários não definidos, atrás dos bastidores ou sentados para jantar.

É possível vê-la nos cartões, que estão à venda. Porém, nos cartões ela é bela, e bela nunca foi. Não acredite nos cartões: ela é uma aberração. A maioria a vê no palco. Mas no palco ela é irreconhecível. Pó de arroz, rouge, máscara de cílios e cabelos postiços cobrem o seu rosto, como uma máscara. O mesmo ocorre nos concertos.

3 Quase (Latim). 
Quando interpreta Margarida, ela, com vinte e sete anos, com rugas, desajeitada, o nariz coberto de sardas, parece uma garota esbelta e atraente de dezessete. No palco é onde ela menos se parece consigo mesma.

Se os senhores quiserem vê-los, consigam o direito de estarem presentes nos almoços, que são organizados para ela e que às vezes ela própria organiza antes de viajar de uma capital para outra. Conseguir esse direito só é fácil à primeira vista, apenas pessoas escolhidas podem chegar à mesa do almoço... Estes últimos incluem cavalheiros revisores, penetras que fingem ser revisores, cantores nativos, regentes e maestros, amadores e apreciadores com cabelos alisados que escondem a careca, transformados em frequentadores e bajuladores teatrais graças ao ouro, à prata e ao parentesco. Esses almoços não são nada entediantes, para uma pessoa observadora são até interessantes... Vale a pena almoçar um par de vezes.

Os famosos (que são muitos entre os que almoçam) comem e conversam. A postura deles é livre: o pescoço para um lado, a cabeça para outro, um cotovelo na mesa. Os idosos até catucam os dentes.

Jornalistas ocupam as cadeiras mais próximas da dela. Estão quase todos bêbados e se mantêm notavelmente atrevidos, como se a conhecessem há cem anos. Se exagerassem mais um grau, seria um desrespeito. Eles contam piadas em voz alta, bebem, interrompem uns aos outros (sem esquecer de dizer: "pardon!"), propõem brindes estrondosos e aparentemente não têm medo de parecerem tolos; alguns chegam a deitar em cima da mesa para beijar a mão dela como gentlemen.

Os que fingem ser revisores conversam com amadores e apreciadores. Os amadores e apreciadores ficam calados. Eles invejam os jornalistas, sorriem alegremente e bebem apenas vinho tinto, que é particularmente bom nesses almoços.

Ela, a rainha do almoço, está vestida de forma despretensiosa, mas muito cara. Um diamante graúdo aparece por baixo da faixa de renda no pescoço. Em ambas as mãos há uma massiva e elegante pulseira. $O$ penteado é extremamente indefinido: as damas gostam, os homens não. $\mathrm{O}$ rosto dela é radiante e 
derrama um largo sorriso para toda a companhia que almoça. Ela consegue sorrir para todos de uma só vez, conversar com todos de uma só vez, acenar de forma adorável com a cabeça, todas as pessoas no almoço recebem um aceno de cabeça. Observem o rosto dela e lhes parecerá que só há amigos ao seu redor e que ela nutre por eles a mais amigável disposição. No fim do almoço ela presenteia alguém com seus cartões; ali mesmo na mesa escreve no verso do cartão o nome e o sobrenome do destinatário sortudo e o autógrafo. É claro que ela conversa em francês, e no fim do almoço em outras línguas também. Em inglês e alemão fala tão mal que chega a ser ridículo, mas até mesmo esse defeito parece adorável vindo dela. Geralmente ela é tão agradável, que o senhor esquece por um longo período de tempo que ela é uma aberração.

E ele? Ele, le mari d'elle, ${ }^{4}$ está sentado a cinco cadeiras dela, bebendo e comendo muito, passa bastante tempo em silêncio, faz bolinhas com o pão e relê os rótulos das garrafas. Ao olhar para a sua figura, sente-se que ele não tem nada para fazer, está entediado, com preguiça, cansado...

Ele tem cabelos loiros com uma calvície que percorre a sua cabeça em trilhas. Mulheres, vinho, noites em claro e o arrastar-se pelo mundo passaram como um arado pelo seu rosto e deixaram rugas profundas. Ele tem trinta e cinco anos, e não mais, mas aparenta ser mais velho. $O$ rosto parece ter ficado de molho no kvas. ${ }^{5}$ Tem olhos bons, mas preguiçosos... Nem sempre foi uma aberração, mas agora é. Pernas arqueadas, braços de cor terrena, pescoço cabeludo. Graças a essas pernas tortas e a um jeito estranhamente particular de andar, por alguma razão, o chamam de "caleche" na Europa. Em seu fraque ele lembra uma gralha molhada com a cauda seca. As pessoas que almoçam nem notam sua presença. Ele os paga com a mesma moeda.

Se vocês conseguirem ir ao almoço, olhem para eles, para esse casal, observem e me digam, o que atou e continua prendendo essas duas pessoas.

40 marido dela (Francês).

5 Bebida tradicional russa fermentada à base de pão. 
Olhando para eles, responderão (obviamente, mais ou menos) que:

- Ela é uma cantora famosa, ele é apenas o marido de uma cantora famosa, ou, para expressar com um termo dos bastidores, marido de sua esposa. Ela ganha ao ano até oitenta mil em moeda russa, ele não faz nada, portanto, ele tem tempo para ser o criado dela. Ela precisa de um contador e de um homem que lide com os empresários, contratos, acordos... Ela conhece apenas o público que aplaude, quanto ao caixa, ela não toma parte do lado prosaico de seu trabalho, não quer saber disso. Consequentemente, ela precisa dele, precisa como de um lacaio, de um criado... Ela o expulsaria se soubesse como administrar isso sozinha. Já ele, apesar de receber dela um sólido salário (ela não conhece o valor do dinheiro!), a rouba junto com as suas camareiras, como duas vezes dois são quatro, ele torra o dinheiro dela, farreia sem parar, talvez até mesmo guarde dinheiro para um dia ruim - e está confortável com a própria posição, assim como um verme que conseguiu entrar em uma boa maçã. Ele a teria deixado, se ela não tivesse dinheiro.

Assim pensam e falam todos aqueles que os observam durante os almoços. Pensam e falam dessa forma, porque, por serem incapazes de penetrar na profundidade do assunto, podem apenas julgar superficialmente. Olham para ela, como que para uma diva, já ele é evitado, como um pigmeu coberto com gosma de sapo; e ainda assim essa diva europeia está ligada a esse sapo por um invejável e nobre laço.

Eis o que ele escreveu:

"Me perguntam, por que eu amo essa megera? É verdade, essa mulher não merece amor. Ela também não merece o ódio. A única coisa que ela merece é que não prestem atenção nela, que ignorem a sua existência. Para amá-la ou você precisa ser eu, ou ser um louco, o que, a propósito, é a mesma coisa.

Ela não é bonita. Quando nos casamos, ela era uma aberração, e agora mais ainda. Não tem testa; no lugar das sobrancelhas acima dos olhos estão duas tiras quase imperceptíveis; ao invés de olhos há duas fendas rasas. Nada brilha nessas fen- 
das: nem intelecto, nem desejos, nem paixão. O nariz é como uma batata. A boca é pequena, bonita, mas os dentes são horríveis. Ela não tem peito e nem cintura. De qualquer forma, essa última falha é suavizada, por sua diabólica, e de alguma forma sobrenatural, habilidade de apertar o espartilho com destreza. Ela é baixinha e robusta. Sua robustez é flácida. En masse, ${ }^{6}$ o defeito que eu acho mais proeminente em seu corpo inteiro é a completa falta de feminilidade. A palidez da pele e a flacidez dos músculos eu não conto como feminilidade, e, nesse sentido, discordo da visão de muitos outros. Ela não é uma dama, nem uma senhora, mas uma lojista com modos desajeitados: quando caminha - sacode os braços, ao sentar coloca uma perna sobre a outra balançando todo o corpo para trás e para frente, ao deitar levanta as pernas, etc...

Ela é desleixada. As suas malas são um exemplo notável disso. Nelas as roupas íntimas limpas estão misturadas com as sujas, punhos de camisas com os saltos e com as minhas botas, espartilhos novos com os danificados. Nunca recebemos ninguém, porque nos nossos quartos sempre reina uma bagunça suja... Ah, o que mais eu posso dizer? Olhe para ela ao meio-dia, quando ela acorda e preguiçosa rasteja para fora do cobertor, e você não reconhecerá nela a mulher com voz de rouxinol. Despenteada, com o cabelo emaranhado, com olhos sonolentos e inchados, em uma camisola com os ombros rasgados, descalça, vesga, envolta por uma nuvem de fumaça do tabaco de ontem - por acaso, ela parece um rouxinol?

Ela bebe. Bebe como um hussardo, a qualquer hora e qualquer coisa. Já bebe faz tempo. Se ela não bebesse, estaria acima da Patti, ${ }^{7}$ ou, pelo menos, não abaixo. Metade de sua carreira ela vem bebendo e em breve vai beber a outra metade. Patifes alemães a ensinaram a beber cerveja, e agora ela não se deita sem beber duas ou três garrafas para chamar o sono. Se não bebesse, não teria gastrite.

Ela é mal-educada e as testemunhas disso são os estudantes que às vezes a convidam para os seus concertos.

6 Em geral (Francês).

7 Adelina Patti (1843 -1919) foi uma famosa cantora italiana. 
Ela ama publicidade. A publicidade nos custa anualmente alguns milhares de francos. Eu desprezo a publicidade com toda a minha alma. Por mais cara que seja essa estúpida propaganda, ela sempre será mais barata que a voz dela. Minha esposa ama que lhe passem a mão na cabeça, não gosta que digam sobre ela uma verdade que não pareça um elogio. Para ela um beijo de Judas comprado é mais agradável do que uma crítica não comprada. É uma completa falta de consciência de dignidade própria!

Ela é inteligente, mas seu intelecto não foi suficientemente educado. Seus miolos há muito perderam a elasticidade; cobertos de gordura, adormeceram.

Ela é geniosa, volúvel, não tem nenhuma convicção duradoura. Ontem disse que o dinheiro é uma bobagem, que o ponto principal não é ele, já hoje fará concertos em quatro lugares, porque chegou à convicção de que não há nada superior ao dinheiro. Amanhã vai dizer o que disse ontem. Ela não quer saber da pátria, não tem heróis políticos, nem um jornal preferido, nem autores preferidos.

Ela é rica, mas não ajuda os pobres. Mais que isso, muitas vezes nem paga tudo o que deve aos modistas e aos cabeleireiros. Ela não tem coração.

Mil vezes uma mulher podre!

Mas olhe para essa megera, quando ela, toda pintada, com o cabelo alisado, espremida, se aproximada da rampa, para começar a competir com rouxinóis e com uma cotovia que saúdam um amanhecer de maio. Quanta dignidade e quanto charme há nesse caminhar de cisne! Dêem uma olhada, eu vos suplico, prestem atenção. Quando ela pela primeira vez levanta a mão e abre a boca, as suas pequenas fendas se transformam em grandes olhos e enchem-se de brilho e paixão... Em nenhum outro lugar você encontraris olhos tão maravilhosos. Quando ela, minha esposa, começa a cantar, quando os primeiros gorjeios se espalham pelo ar, quando eu começo a sentir que sob o efeito desses sons maravilhosos a minha alma conturbada se acalma, olhem para o meu rosto e então o mistério do meu amor será revelado a vocês. 
- Ela é admirável, não é? - às vezes pergunto aos meus vizinhos.

Eles dizem "sim", mas para mim é pouco. Quero aniquilar aquele que ouse pensar que essa mulher extraordinária não é minha esposa. Esqueço tudo o que houve antes e vivo apenas o presente.

Vejam, que atriz ela é! Quanta profundeza de significado ela esconde em cada movimento! De tudo ela entende: tanto o amor, quanto o ódio, e a alma humana... Não é por acaso que o teatro se desfaz em aplausos.

Ao fim do último ato eu a conduzo para fora do teatro pálida, exausta, em uma noite viveu uma vida inteira. Também estou pálido e exausto. Nós pegamos uma carruagem e vamos para o hotel. No hotel ela, calada, sem tirar a roupa, se joga na cama. Eu me sento em silêncio na beirada da cama e beijo sua mão. Nessa noite ela não me afasta. Adormecemos juntos, dormimos até de manhã e acordamos, para mandar um ao outro para o inferno e...

Sabe quando eu ainda a amo? Quando ela faz presença em bailes ou almoços. Aqui também amo nela a atriz formidável. De fato, precisa ser uma atriz e tanto para ser capaz de enganar e dominar a sua própria natureza do jeito como ela sabe fazer. Eu não a reconheço nesses estúpidos almoços... De um pato depenado ela faz um pavão..."

Essa é uma carta escrita com uma caligrafia de bêbado, quase ilegível. Foi escrita em alemão e está salpicada de erros ortográficos.

Eis o que ela escreve:

"Vocês me perguntam se eu amo esse garoto? Sim, às vezes... Por quê? Só Deus sabe...

É verdade, ele não é bonito e não tem uma boa aparência. Pessoas como ele não nasceram para ter o direito de ter um amor recíproco. Pessoas como ele podem apenas comprar o amor, já que este não lhes é entregue de graça. Tirem as suas próprias conclusões.

Dia e noite ele está trocando as pernas. As suas mãos tremem, o que é bastante feio. Quando está bêbado, resmunga e 
briga. Ele bate em mim também. Quando está sóbrio, fica deitado sem dizer nada todo desleixado.

Ele está sempre vestido em farrapos, embora não falte dinheiro para roupas. Metade dos meus ganhos escorrega por suas mãos, não se sabe para onde.

De forma nenhuma vou controlá-lo. As desafortunadas atrizes casadas têm contadores terrivelmente caros. Os maridos recebem metade dos lucros por seus trabalhos.

Ele não gasta com mulheres, disso eu sei. Ele as despreza.

Ele é preguiçoso. Eu nunca o vi fazer coisa alguma. Bebe, come, dorme e só.

Ele não terminou nenhum curso. Foi expulso do primeiro ano na universidade por insolências.

Ele não é nobre, e pior de tudo, é alemão.

Eu não gosto dos senhores alemães. Para cem alemães, há noventa e nove idiotas e um gênio. O último eu descobri graças a um príncipe, alemão com um forro francês.

Ele fuma um tabaco abominável.

Mas ele tem lados bons. Ama a minha nobre arte mais do que eu. Quando anunciam, antes de um espetáculo, que estou doente e não posso cantar, isto é, fazendo birra, ele se arrasta como um cadáver e aperta os punhos.

Ele não é covarde e não tem medo dos outros. Isso é o que eu mais amo nas pessoas. Vou contar aos senhores um pequeno episódio da minha vida. Isso aconteceu em Paris, um ano após a minha saída do conservatório. Eu era então muito jovem e estava aprendendo a beber. Farreava todas as noites, o tanto quanto as minhas forças juvenis aguentavam. Festejava, naturalmente, acompanhada. Em uma dessas farras, quando estava brindando com meus nobres admiradores, um garoto muito feio e desconhecido veio até a mesa e, olhando diretamente para os meus olhos, perguntou:

- Por que a senhora está bebendo?

Nós gargalhamos. 0 meu garoto não se intimidou.

A segunda pergunta foi mais ousada e saiu diretamente da 
alma:

- Do que você está rindo? Os patifes, que agora estão embebedando a senhora com vinho, não lhe darão nem uma moeda quando a senhora perder sua voz por causa da bebida e se tornar uma miserável!

Que tal uma insolência dessas? A minha companhia começou a se revoltar. Enquanto isso, eu já havia colocado o garoto ao meu lado e ordenado que lhe servissem vinho. Acontece que o defensor da sobriedade revelou-se um ótimo bebedor de vinho. A propôs. ${ }^{8}$ eu o chamo de garoto apenas porque ele tem os bigodes muito pequenos.

Paguei pela sua insolência com o casamento.

$\mathrm{O}$ que ele mais faz é ficar em silêncio. Na maioria das vezes fala apenas uma palavra. Essa palavra ele fala com uma voz grave, com um tremor na garganta e um espasmo no rosto. Ele pronuncia essa palavra quando ele está sentado entre as pessoas, durante o almoço, no baile... Quando alguém (quem quer que seja) conta uma mentira, ele levanta a cabeça e, sem olhar para nada e sem ficar acanhado, fala:

- Mentira!

Essa é a palavra preferida dele. Que mulher resistiria ao brilho nos olhos, com o qual essa palavra é pronunciada? Eu amo essa palavra, esse brilho e esse espasmo no rosto. Nem todos sabem pronunciar essa palavra tão boa, ousada, mas meu marido a fala em qualquer lugar e sempre. Eu o amo às vezes, e esse "às vezes", até onde bem me lembro, coincide com a pronúncia dessa boa palavra. De qualquer forma, só Deus sabe porque o amo. Sou uma má psicóloga, mas, neste caso, parece que é uma questão psicológica que está em jogo...”

Esta carta foi escrita em francês, com uma maravilhosa, quase masculina caligrafia. Nela você não encontrará um só erro gramatical.

8 A propósito (Francês). 


\section{Referências Bibliográficas}

QUEIROZ, Sônia (org.). Glossário de termos de edição e tradução. Belo Horizonte: Viva Voz (FALE/UFMG), 2008. Disponível em:

http://escritoriodolivro.com.br/bibliografia/glossarioedicaoetraducao.pdf Acesso em: Abril de 2020.

TCHÉKHOV, Anton. On i Ona. In: Pólnoie sobránie sotchiniéni i píssem $v 30$ tomakh. (Obra completa em 30 volumes). Volume 1. Moscou: Naúka, 1974, pp. 239-246.

Recebido: em 20/03/2019

Aceito em 03/04/2020

Publicado: em junho de 2020 